DOI: 10.12957/demetra.2017.26754

\title{
Aspecto higiênico-sanitário de sorvetes artesanais e industriais: análise da variabilidade genética e da resistência a antimicrobianos em Escherichia coli isoladas
}

\author{
Hygienic-sanitary aspect of artisanal and industrial ice creams: analysis of genetic variability \\ and antimicrobial resistance in Escherichia coli isolated
}

\author{
Amanda Pires Andrade ${ }^{l}$ \\ Daniela Ercole Dale Luche' \\ Eliane Patrícia Cervelatti \\ Denise Junqueira Matos \\ ${ }^{\prime}$ Centro Católico Salesiano Auxilium de \\ Araçatuba, Curso de Ciências Biológicas. \\ Araçatuba-SP, Brasil. \\ Correspondência / Correspondence \\ Daniela Ercole Dale Luche \\ E-mail: daniela.luche@hotmail.com
}

\section{Resumo}

Objetivo: O presente trabalho teve como objetivo avaliar o aspecto higiênico-sanitário de sorvetes artesanais e industriais e analisar a variabilidade genética e a resistência a antimicrobianos em isolados de Escherichia coli. Métodos: Foram compradas 27 amostras de sorvetes, detectando coliformes totais a $30-35^{\circ} \mathrm{C}$ por fermentação em tubos múltiplos. Os tubos com positividade foram inoculados em caldo EC e em ágar SS para detecção de Escherichia coli e Salmonella spp, respectivamente. Para testes antimicrobianos, utilizou-se técnica de difusão em placas, discriminando níveis de resistência. A variabilidade genética foi diagnosticada pelas técnicas PCR-RAPD e ERIC-PCR através do grau polimórfico determinado pelo padrão de bandas. Resultados e Discussão: A partir das amostras microbiológicas, houve positividade para E. coli $(48 \%)$ e Salmonella spp (22\%). Os testes de resistência a antimicrobianos em E. coli diagnosticaram resistência para $85 \%$ das amostras obtidas, sendo que destas, $34 \%$ apresentaram-se multirresistentes. Encontrou-se um alto grau de polimorfismo nos testes PCR-RAPD e ERIC-PCR, demonstrando a grande variabilidade gênica entre as bactérias. Conclusão: As amostras apresentaram condições insatisfatórias, oferecendo riscos à saúde dos consumidores. O teste antibiograma expressou resistência e multirresistência, enquanto os testes PCR-RAPD e ERIC-PCR indicaram grande variabilidade genética entre as bactérias, considerando múltiplas fontes de contaminação. Portanto, medidas para controlar a prevenção da contaminação são tidas como importantes.

Palavras-chave: Alimentação. Enterobactérias. Mutação. Antibacteriano. Sorvete. 


\section{Abstract}

Objective: The aim of the present study was to verify the Hygienicsanitary aspect of artisanal and industrial ice creams and antimicrobial resistance in Escherichia coli isolated. Methods: 27 ice cream samples were purchase, detecting total coliforms at 30-35 ${ }^{\circ} \mathrm{C}$ by fermentation in multiple tubes. The tubes with positivity were inoculated in EC Broth and SS agar for the detection of Escherichia coli and Salmonella spp, respectively. To antimicrobial tests, plaque diffusion technique was used, discriminating levels of resistance. Genetic variability was diagnosed by the PCR-RAPD and ERIC-PCR techniques through the polymorphic degree determined by the band pattern. Results and Discussion: From the microbiological samples, there was positivity for E. coli (48\%) and Salmonella spp (22\%). The antimicrobial resistance tests in E. coli diagnosed resistance to $85 \%$ of the samples obtained, whereas $34 \%$ were multiresistant. A high degree of polymorphism was found in the PCR-RAPD and ERIC-PCR tests, demonstrating the great genetic variability between the bacteria. Conclusion: The samples presented unsatisfactory conditions, offering hazards to the consumers' health. The antibiogram test expressed resistance and multiresistance, while the PCR-RAPD and ERIC-PCR tests indicated great genetic variability among the bacteria, considering multiple sources of contamination. Therefore, measures to control contamination prevention are considered important.

Keywords: Feeding. Enterobacteria. Mutation. Anti-bacterials. Ice cream.

\section{Introdução}

Sorvete é um gelado comestível, obtido pela emulsão de gorduras e proteínas, com ou sem a adição de outros ingredientes e substâncias, submetidas ao congelamento. ${ }^{1}$ Os sorvetes podem ser classificados como: massa ou cremosos, picolés e produtos especiais gelados e devem ser conservados sob temperatura adequada durante o transporte e armazenamento, para a manutenção da qualidade do produto. ${ }^{2,3}$

Os sorvetes podem apresentar laticínios e/ou ovos em sua composição, nesse caso, devem ser submetidos ao tratamento térmico, conforme descrito na Resolução SAA - 03, de 10 de janeiro de 2008, pois podem causar surtos de doenças transmitidas por alimentos (DTA), uma vez que apresentam potencial risco de contaminação de natureza biológica..$^{2-4,5-7}$ 
Os surtos de DTA podem ser causados por bactérias da família enterobacteriaceae, como a Salmonella spp e Escherichia coli, bactérias gram-negativas que são potenciais riscos biológicos. Esses microrganismos são responsáveis por graves intoxicações alimentares e por surtos registrados em vários países. Além do mais, podem causar manifestações potencialmente letais ao indivíduo, sendo os imunocomprometidos e debilitados, crianças, idosos e gestantes altamente suscetíveis. ${ }^{3,8-11}$

Entre as bactérias isoladas mais comuns em amostras clínicas, as enterobactérias são as principais responsáveis pelas infecções hospitalares, intestinais e extraintestinais, localizadas ou sistêmicas, além de acometimento de vias urinárias, pulmões, sistema nervoso central, pele, mucosas e meninges. ${ }^{12}$ Por habitar, naturalmente, o intestino humano, a presença destes microrganismos em alimentos indica contaminação fecal, revelando a deficiência das condições higiênico-sanitárias. 8, 12-15

Após a descoberta dos antibióticos, o tratamento das doenças infecciosas com elevado grau de morbidade e mortalidade teve um grande avanço terapêutico. Porém, o uso prolongado ou indiscriminado dessas drogas tem favorecido o aumento da resistência bacteriana e os avanços das indústrias farmacêuticas não conseguem acompanhar na descoberta de novas drogas. Isso interfere no tratamento e controle efetivo das infecções por estes agentes. ${ }^{5,16}$

As bactérias têm a capacidade de se adaptarem ao ambiente, o que está associado à estrutura genômica, permitindo a troca de genes entre elas, originando assim uma diversidade alélica determinada como variabilidade genética. ${ }^{17}$ A partir de testes laboratoriais, como Reação em Cadeia da Polimerase - DNA polimórfico amplificado aleatoriamente (PCR-RAPD) e Sequência Repetitiva Intergênica de enterobactérias - Reação em Cadeia da Polimerase (ERIC-PCR), que buscam estabelecer parâmetros genéticos que permitem agrupar isolados, é possível detectar meios de reprodução, níveis de migração, evolução e dispersão de uma espécie, como também sua habilidade de adaptação às mudanças ambientais. ${ }^{18,19}$

Com base no que foi aludido, objetivou-se avaliar o aspecto higiênico-sanitário de sorvetes artesanais e industriais e analisar a variabilidade genética e resistência a antimicrobianos em isolados de Escherichia coli.

\section{Material e Métodos}

Foram compradas, aleatoriamente, 27 amostras de sorvetes artesanais e industriais: 22 do tipo massa ou cremosos e cinco do tipo picolé. Os sorvetes foram obtidos entre os meses de março e setembro de 2016, em estabelecimentos comerciais de Araçatuba, Promissão, Piacatu, Rinópolis e Gabriel Monteiro, no Estado de São Paulo.

Obtenção das amostras: Os sorvetes de massa foram obtidos em estabelecimentos como shoppings, sorveterias e lanchonetes como self-service, e os picolés, retirados diretamente de freezers de lojas 
de conveniência. Foram utilizados os utensílios e recipientes oferecidos pelo estabelecimento, retratando as condições com que o consumidor recebe o produto. Os sorvetes foram transportados em caixas isotérmicas até o laboratório de microbiologia e biologia molecular do Centro Universitário Católico UniSalesiano Auxilium, Araçatuba-SP onde foram realizadas as análises.

Pesquisa de coliformes totais $\left(30-35^{\circ} \mathrm{C}\right)$, termotolerantes $\left(45^{\circ} \mathrm{C}\right)$ e E. coli: Foi realizada pela técnica de fermentação em tubos múltiplos. ${ }^{20} \mathrm{~A}$ partir da amostra em estado líquido, pipetou-se $1 \mathrm{~mL}$ em tubos contendo Água peptonada (ACUMEDIA) 1\%, obtendo-se a amostra concentrada; após homogeneização, $1 \mathrm{~mL}$ desta foi transferido a outro tubo, obtendo-se a diluição $10^{-1}$, e deste, uma alíquota de $1 \mathrm{~mL}$ foi utilizada para obtenção da diluição $10^{-2}$. Alíquotas de $1 \mathrm{~mL}$ de amostra concentrada e suas diluições $10^{-1}$ e $10^{-2}$ foram pipetadas em série de três tubos com rosca contendo $9 \mathrm{ml}$ do meio de cultura Caldo Verde Brilhante Lactose Bile 2\% (CVBLB) (KASVI) com Tubos Duhran invertidos para detecção de coliformes a $35^{\circ} \mathrm{C}$. A positividade foi confirmada pela captação de gás no interior dos tubos Duhran liberados durante a fermentação bacteriana.

A partir dos tubos positivos, foram repicados $1 \mathrm{~mL}$ da amostra em caldo Escherichia coli Broth (EC) (KASVI) para detecção de coliformes a $45^{\circ} \mathrm{C}$, seguindo a mesma técnica de fermentação em tubos múltiplos. Os tubos foram acondicionados em estufa bacteriológica a $35^{\circ} \mathrm{C} \pm 2$ (CVBLB) e banho-maria a $45^{\circ} \mathrm{C} \pm 2$ (EC) por 48 horas.

Isolados de E. coli e Salmonella spp conhecidos foram inoculados juntamente com as amostras como controle positivo, e o controle negativo sucedeu pela inoculação do meio de cultura sem amostragem. Testes fora dos padrões foram refeitos.

O Número Mais Provável (NMP) por mililitro de cada amostra de sorvete foi quantificado conforme os padrões estabelecidos pela Resolução RDC no 12, de 2 de janeiro de 2001, que prevê padrões máximos aceitáveis para alimentos de $10^{2} / \mathrm{g}$ para coliformes a $35^{\circ} \mathrm{C}$, e $5,0 \times 10$ para coliformes a $45^{\circ} \mathrm{C} . .^{21}$

Detecção de Salmonella spp: O meio CVBLB foi utilizado para selecionar somente bactérias gram-negativas. Sendo assim, apenas os tubos que apresentaram positividade foram repicados para placas de Petri contendo o meio Salmonella-Shigella ágar (SS) (HIMEDIA). As placas foram

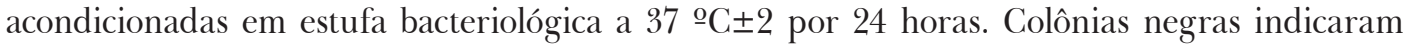
positividade. ${ }^{22}$

Isolamento e armazenamento de E. coli: As amostras positivas no caldo EC foram repicadas em meio de cultura sólido Eosina azul de metileno (EMB) (KASVI). As placas foram mantidas em estufa bacteriológica a $37^{\circ} \mathrm{C} \pm 2$ por 24 horas. Colônias verdes metálicas indicaram positividade.

Perfil de resistência aos antimicrobianos: As amostras que apresentaram positividade no caldo EC foram inoculadas em ágar MacConkey (KASVI) e mantidas em estufa bacteriológica a $37^{\circ} \mathrm{C} \pm 2$ 
por 18-24 horas. Colônias róseas isoladas, indicativas de E. coli, foram transferidas para tubos contendo caldo Lyptone Soya Broth (HIMEDIA) para ajuste do padrão do inóculo com auxílio de um turbidímetro em 0,5 da escala de McFarland (1,5 x $\left.10^{8} \mathrm{UFC} / \mathrm{mL}\right)$. Utilizando-se a técnica de difusão em placas, as amostras foram semeadas em meio ágar Muller Hinton (KASVI), onde foram colocados discos Sensidisc DME dos seguintes antibióticos: Cefalotina (30 $\mu \mathrm{g})$, Imipenem (10 $\mu \mathrm{g})$, Gentamicina (120 $\mu \mathrm{g})$, Ciprofloxacina (05 mcg), Ácido nalidíxico (30 $\mu \mathrm{g})$, Cloranfenicol $(30 \mu \mathrm{g})$ e Nitrofurantoína $(300 \mu \mathrm{g}){ }^{14,23,24}$ As placas foram conservadas a $37{ }^{\circ} \mathrm{C} \pm 2$ por 24 horas. A leitura foi realizada de acordo com as recomendações do fabricante (DME), medindo-se o diâmetro em milímetros dos halos obtidos e classificando-se a amostra como resistente, intermediária e sensível a cada antibiótico utilizado.

Análise da variabilidade genética dos isolados de E. coli: Foram retiradas duas colônias isoladas do ágar MacConkey e suspensas em $200 \mu \mathrm{l}$ de água ultrapura.$^{25}$ Desta suspensão foram retiradas $2 \mu \mathrm{l}$ para as reações de PCR-RAPD e ERIC-PCR, a fim de analisar a variabilidade genética.

Para uma reação de volume final de $25 \mu \mathrm{l}$, foram utilizados $2 \mu \mathrm{l}$ de suspensão de células como DNA molde, 2,5 mM de cada dNTP, 1,75 mM de $\mathrm{MgCl}_{2}$, $1 \mathrm{X}$ de tampão Taq DNA polimerase, $1 \mathrm{U}$ de Taq Polimerase, $400 \mathrm{ng} / \mu \mathrm{l}$ de primer OPA12 (5’ CAATCGCCGT 3') ou Ecoli-2 (5’AGAAGCGATG 3') para o teste RAPD e $400 \mathrm{ng} / \mu \mathrm{l}$ de cada um dos oligonucleotídios ERIC1R (5’ TGTAGGCTCGTGGGATTCAC 3’) e ERIC2R (5’AAGTAAGTGACTGGGGTGAGCG 3’) para a técnica ERIC-PCR. ${ }^{19}$

A reação de amplificação para o RAPD foi iniciada com a desnaturação a $94^{\circ} \mathrm{C}$ por três minutos seguidos de 45 ciclos de 1 minuto a $94{ }^{\circ} \mathrm{C}, 1$ minuto a $30{ }^{\circ} \mathrm{C}$ e 2 minutos a $72{ }^{\circ} \mathrm{C}$, finalizando com uma extensão de $72{ }^{\circ} \mathrm{C}$ por 5 minutos. Para a técnica ERIC-PCR, a reação contou com um ciclo inicial de desnaturação a $94{ }^{\circ} \mathrm{C}$ por 7 minutos, seguido de 30 ciclos de desnaturação a $94{ }^{\circ} \mathrm{C}$ por 1 minuto e 30 segundos, anelamento a $51{ }^{\circ} \mathrm{C}$ por 1 minuto, extensão a $72{ }^{\circ} \mathrm{C}$ por 1 minuto e 30 segundos e um ciclo final de extensão a $72{ }^{\circ} \mathrm{C}$ por 15 minutos. As reações de amplificação foram realizadas em um termociclador "Amplitherm termal cyclers". Os produtos de amplificação foram separados em gel de agarose $1,5 \%$, utilizando-se marcador de peso molecular 100 pb ladder como referência. Os fragmentos foram visualizados em transiluminador de luz ultravioleta. ${ }^{26}$

As bandas visíveis no gel de agarose foram convertidas em matriz binária, estabelecendo 1 para bandas presentes e 0 para a bandas ausentes. $O$ grau de similaridade (Jaccard) foi determinado pelo coeficiente de concordância simples, relacionando a presença (1) e ausência (0) de banda, e os respectivos dendogramas foram construídos com auxílio do programa Past 2.17, versão 2013. 


\section{Resultados e Discussão}

A presença de coliformes totais foi observada em 25 amostras (93\%), sendo 20 de sorvete de massa e cinco de picolé. Destas amostras, 16 (61\%) apresentaram coliformes termotolerantes. De modo geral, $44 \%$ e $7 \%$ das amostras apresentaram contagens fora dos padrões para coliformes a $35^{\circ} \mathrm{C}$ e a $45^{\circ} \mathrm{C}$, respectivamente (Tabela 1 ).

Tabela 1. Aspectos microbiológicos de amostras de sorvetes de Araçatuba-SP e região em 2016.

\begin{tabular}{cccccc}
\hline Microrganismo & Unidade & $\begin{array}{c}\text { Padrão } \\
\text { federal* }\end{array}$ & Contagem & $\mathrm{N}^{\circ}$ amostras & $\%$ \\
\hline $\begin{array}{c}\text { Coliformes totais } \\
\left(35^{\circ} \mathrm{C}\right)\end{array}$ & $\mathrm{NMP} / \mathrm{g}$ & $10^{2} / \mathrm{g}$ & $\begin{array}{c}<11^{1}-10^{2} \\
11^{2}->11^{2}\end{array}$ & $\begin{array}{c}10 \\
12\end{array}$ & 37 \\
& & & 0 & 10 & 37 \\
\hline $\begin{array}{c}\text { Coliformes } \\
\text { termotolerantes } \\
\left(45^{\circ} \mathrm{C}\right)\end{array}$ & $\mathrm{NMP} / \mathrm{g}$ & \multirow{2}{*}{$5,0 \times 10$} & $1 \mathrm{a} 49$ & 15 & 56 \\
\hline Salmonellaspp & \multirow{2}{*}{$\mathrm{Em} 25 \mathrm{~g}$} & \multirow{2}{*}{ Negativo } & Positivo & 6 & 7 \\
\hline
\end{tabular}

* Padrões microbiológicos segundo a RDC no 12, de 2 de janeiro de 2001 e Portaria no 451, de 19 de setembro de 1997.

Por se tratar de amostras de origem alimentícia, o alto índice de tais bactérias pode levar o consumidor a um quadro infeccioso. ${ }^{27} \mathrm{~A}$ contaminação pode ser proveniente de uma má condição higiênico-sanitária durante todo o processo de fabricação do sorvete, assim como durante o tratamento térmico, principalmente em pequenos comércios artesanais, onde os manipuladores dificilmente são conscientizados por meio de uma política de qualidade eficiente sobre o risco de contaminações. ${ }^{21,28}$ Presumindo que a E. coli é uma das principais causadoras de diarreia, e que, segundo a Organização Mundial da Saúde (OMS), quase 2 milhões de crianças morrem todos os anos no mundo por conta dessa disfunção, sendo 200 mil somente no Brasil, sua presença em sorvetes gera uma alarmante preocupação quanto à situação de saúde pública. ${ }^{29,30}$

Resultados semelhantes foram encontrados em Araraquara-SP, onde, das 24 amostras de sorvetes não pasteurizados, 66,6\% não estavam de acordo com os padrões estabelecidos pelo Regulamento da Inspeção Industrial e Sanitária de Produtos de Origem Animal (RIISPOA). ${ }^{31,32}$ Em Arapongas-PR, 21 amostras de sorvetes analisadas (industriais e artesanais) estavam contaminadas por coliformes a $30-35^{\circ} \mathrm{C} .{ }^{6}$ 
Com relação aos testes qualitativos para Salmonella spp, esta foi encontrada em seis (22\%) das amostras (Tabela 1). Além disso, foram observadas larvas de mosca em uma das placas de cultivo, indicando uma possível contaminação com ovos no utensílio coletor de sorvete, já que esta se encontrava inserida em reservatório desprotegido com água contendo restos de sorvetes de lavagens anteriores.

Estima-se que a E. coli e Salmonella spp se diversificaram a partir de um mesmo ancestral, isso explica a similaridade na sintomatologia das doenças causadas por tais bactérias. Há cerca de 100 milhões de anos vêm ocorrendo naturalmente mutações e seleções gênicas, dando origem aos microrganismos distintos atuais. ${ }^{30,33}$

Resultados positivos para Salmonella spp foram encontrados em Fortaleza-CE, onde $75 \%$ das amostras de sorvetes estavam em desacordo com a Resolução da ANVISA no 12, de 2 de janeiro de 2001, que prevê a ausência da bactéria em qualquer produto alimentício. ${ }^{21,34}$ Cepas de Salmonella $s p p$ podem ser destruídas durante a pasteurização, porém o alimento pode ser recontaminado por materiais, equipamentos e mãos dos manipuladores má higienizadas. ${ }^{35}$

Nos Estados Unidos, o Centro de Comunicação de Doenças (CDC) estima que 95\% das contaminações por Salmonella spp são de origem alimentar. Já a Rede de Vigilância Ativa de doenças de origem alimentar (FoodNet) considera que, de 1,4 milhão de casos anuais de salmonelose, 1,3 milhão são devido ao consumo de alimentos contaminados por Salmonella spp. Esse tipo de contaminação classifica o produto como potencialmente capaz de causar doença transmitida por alimento (DTA), denominando este como inapropriado para consumo humano. ${ }^{30,36,37}$

Entre 1993 e 1997, no interior de São Paulo, foram analisados 23 surtos ocorridos por Salmonella, verificando que 95,7\% dos casos estavam associados à ingestão de alimentos contendo ovos, sendo $87 \%$ vinculados à ingestão de alimentos à base de ovos crus, como no caso de alguns emulsificantes utilizados em sorvetes. ${ }^{38}$

O contágio por Salmonella spp pode não ter ocorrido por imprudência do fabricante dos sorvetes e sim pela matéria-prima adquirida de ambiente externo, principalmente o ovo in natura. Para garantir que seu produto não se contamine, o ideal seria que o fabricante se certificasse da qualidade dos produtos oferecidos por seus fornecedores.

Quanto ao teste de resistência aos antimicrobianos, 27 (85\%) amostras de E.coli manifestaram resistência a pelo menos um dos agentes antimicrobianos, três (9\%) apresentaram-se com resistência intermediária e apenas 2 (6\%) foram sensíveis. Uma infecção por organismo sensível pode ser tratada com a dose recomendada do fármaco, já por um agente que demonstra resistência intermediária, o tratamento deve ser administrado em dose máxima, se possível, e em caso de bactérias resistentes, o microrganismo não será inibido pelo agente antimicrobiano. ${ }^{39,40}$ 
Os antibióticos mais eficientes foram o Cloranfenicol e a Gentamicina, inibindo 100\% do crescimento bacteriano, seguidos de Ciprofloxacina (94\%), Ácido Nalidíxico (78\%), Imipenem (79\%), Nitrofurantoína (37\%) e Cefalotina (31\%), conforme Figura 1.

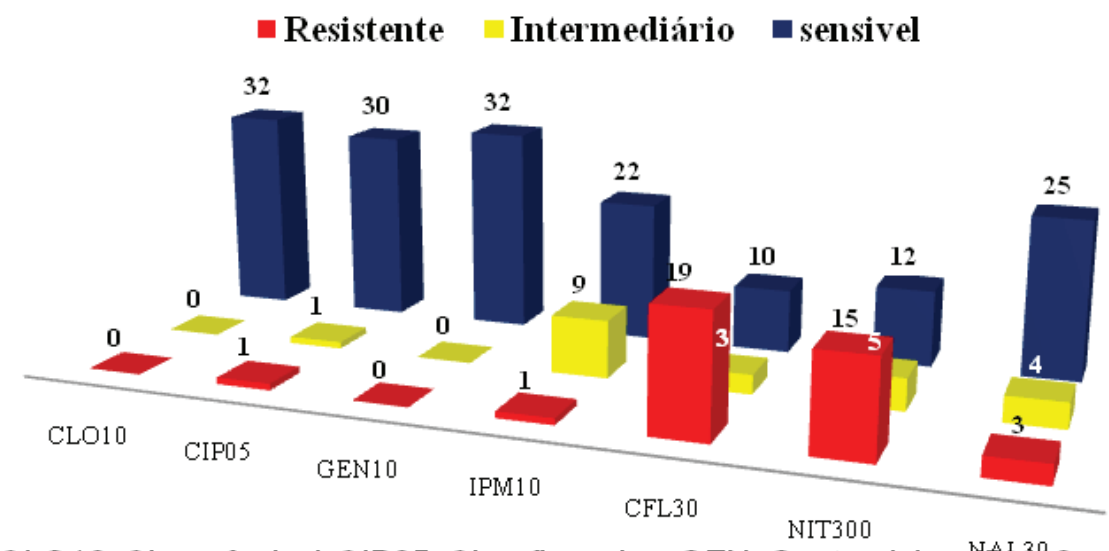

CLO10-Cloranfenicol, CIP05- Ciprofloxacina, GEN- Gentamicina, YPFN 9 0Imipenen, CFL30-Cefalotina, NIT300-Nitrofurantoína e NAL30- Ácido Nalidíxico.

Figura 1. Eficiência dos antimicrobianos em Escherichia coli isoladas de amostras de sorvetes de Araçatuba-SP e região, 2016.

Além disso, 11 amostras (34\%) apresentaram multirresistência aos antimicrobianos, um fator inquietante, pois esses microrganismos surgem com diversos fatores, abrangendo o uso abusivo e inapropriado de antibióticos por parte da população. ${ }^{41,42}$

Os bacilos Gram-negativos analisados foram provenientes de amostras que apresentaram positividade em qualquer concentração e repetição da triplicata. Bactérias de mesma origem amostral apresentaram perfil de resistência diferenciado, conforme exemplos da Tabela 2. 
Tabela 2. Perfil de resistência a antimicrobianos de bactérias de uma mesma origem amostral isoladas de amostras de sorvetes de Araçatuba-SP e região, 2016.

\begin{tabular}{|c|c|c|c|c|c|}
\hline Amostra & Concentração & IPM10 & CFL30 & NIT300 & NAL30 \\
\hline 2 & 10 & $\mathrm{~S}$ & $\mathrm{R}$ & I & $\mathrm{S}$ \\
\hline 2 & 10 & $\mathrm{~S}$ & $\mathrm{R}$ & $\mathrm{S}$ & $\mathrm{R}$ \\
\hline 2 & $10^{-1}$ & $\mathrm{~S}$ & $\mathrm{R}$ & $\mathrm{R}$ & $\mathrm{S}$ \\
\hline 13 & 10 & $\mathrm{~S}$ & $\mathrm{R}$ & $\mathrm{R}$ & $\mathrm{R}$ \\
\hline 13 & $10^{-2}$ & $\mathrm{~S}$ & $\mathrm{R}$ & $\mathrm{S}$ & $\mathrm{S}$ \\
\hline 14 & 10 & $\mathrm{~S}$ & I & $\mathrm{S}$ & $\mathrm{S}$ \\
\hline 14 & $10^{-2}$ & I & $\mathrm{R}$ & $\mathrm{S}$ & $\mathrm{S}$ \\
\hline 19 & 10 & I & $\mathrm{R}$ & $\mathrm{R}$ & $\mathrm{S}$ \\
\hline 19 & 10 & $\mathrm{~S}$ & $\mathrm{R}$ & $\mathrm{R}$ & $\mathrm{S}$ \\
\hline 19 & $10^{-2}$ & $\mathrm{~S}$ & $\mathrm{~S}$ & $\mathrm{R}$ & I \\
\hline 23 & 10 & I & $\mathrm{S}$ & I & $\mathrm{R}$ \\
\hline 23 & 10 & I & $\mathrm{R}$ & $\mathrm{R}$ & I \\
\hline 23 & $10^{-1}$ & $\mathrm{~S}$ & $\mathrm{~S}$ & $\mathrm{~S}$ & $\mathrm{~S}$ \\
\hline 23 & $10^{-2}$ & $\mathrm{R}$ & $\mathrm{R}$ & I & $\mathrm{S}$ \\
\hline 23 & $10^{-2}$ & I & $\mathrm{R}$ & $\mathrm{S}$ & $\mathrm{S}$ \\
\hline 24 & $10^{-1}$ & $\mathrm{~S}$ & $\mathrm{R}$ & $\mathrm{R}$ & $\mathrm{S}$ \\
\hline 24 & $10^{-1}$ & $\mathrm{~S}$ & $\mathrm{~S}$ & $\mathrm{R}$ & I \\
\hline 24 & $10^{-2}$ & $\mathrm{I}$ & $\mathrm{R}$ & $\mathrm{S}$ & $\mathrm{S}$ \\
\hline
\end{tabular}

A mutação genética se desenvolve quando o microrganismo adquire resistência a um antimicrobiano ou se adapta a um meio diferente. Esta é estável e transmitida a gerações sucessivas. A resistência a antibióticos já é um problema global, pois as infecções de maior risco são provocadas pelas superbactérias, que são incontroláveis aos fármacos frequentemente utilizados. ${ }^{43}$

Microrganismos resistentes apresentam fenótipo de resistência marcado por uma concentração mínima inibitória (CMI) para certo tipo de antibiótico. ${ }^{44}$ A bactéria pode ser resistente a um antimicrobiano apenas pelo fato de não possuir a estrutura sobre a qual este exerce sua atividade. 
A resistência adquirida alude o desenvolvimento da estrutura de resistência, obtida por mutação de genes já existentes, ou de materiais vindos de outros microrganismos (transformação, transdução e conjugação) por mutação do material genético adquirido. ${ }^{45}$

Resultados divergentes foram obtidos analisando a resistência antimicrobiana de $E$. coli isoladas de fezes de leitões, em que se verificou níveis elevados de resistência, como 97\% para Cloranfenicol e 86\% para Gentamicina. ${ }^{5}$ Um estudo realizado em 2001 mostra a prevalência de resistência de E. coli 0157: $\mathrm{H7}$ em Cefalotina e Cloranfenicol. ${ }^{46}$

O teste de variabilidade genética demonstrou alto grau de polimorfismo a partir dos dois iniciadores testados no PCR-RAPD e a amplificação revelou um total de 20 bandas, sendo todas polimórficas, indicando a abrangente e considerável variedade gênica entre as bactérias isoladas (Figura 2). Foram obtidas nove bandas com o primer Ecoli2 com tamanho entre 400 pb e 2.080 pb e coeficiente de correlação de similaridade de Jaccard de 0,85. Considera-se forte similaridade para correlações acima de 0,80 . O uso do primer OPA12 revelou a presença de 11 bandas distintas, variando também entre 400 pb e 2.080 pb e coeficiente de correlação de 0,87. Os dendogramas referentes a estes resultados foram obtidos através do programa PAST e estão demonstrados na Figura 3A.

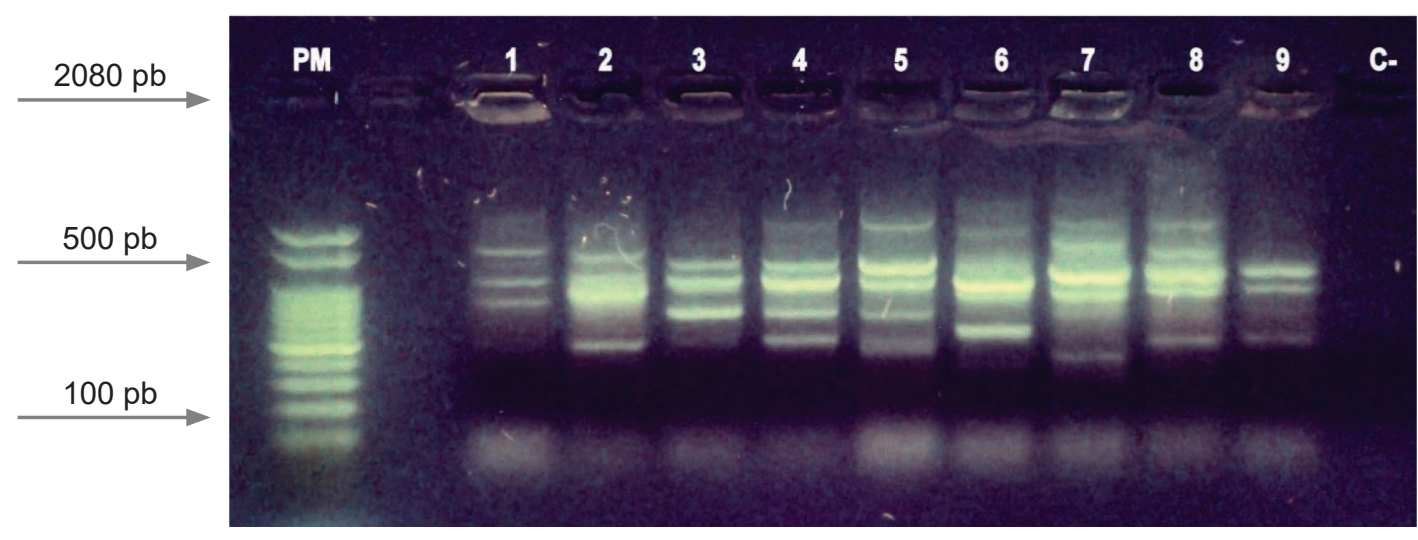

*PM-Peso molecular. Poços 1 a 5 referem-se à amostra 23 e poços 6 a 9 indicam amostra 24.

Figura 2. Divergência gênica de mesma procedência e presença de bandas conservativas de Escherichia coli em amostras de sorvetes de Araçatuba-SP e região, 2016. 


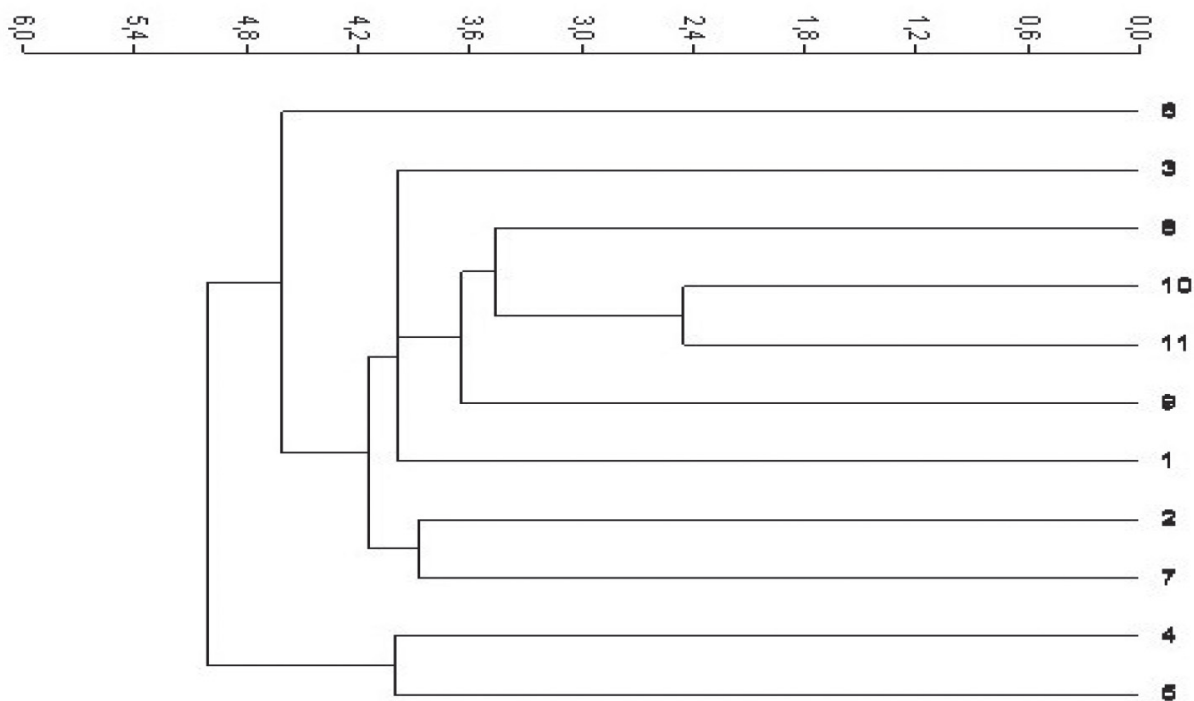

Figura 3A. Teste RAPD utilizando-se primer Ecolil e OPA12, respectivamente.

Bandas distintas também foram obtidas estudando-se amostras de E. coli isoladas da água da Lagoa dos Patos-RS, os padrões de bandas proporcionaram grande variedade genética, com 5 a 15 fragmentos de $150 \mathrm{pb}$ a $1.800 \mathrm{pb}^{47}$

Para o teste ERIC-PCR, foram obtidas 16 bandas que, quando comparadas diretamente com o peso molecular ladder $100 \mathrm{pb}$, apresentaram fragmentos variando entre $100 \mathrm{pb}$ e $1.500 \mathrm{pb}$ e coeficiente de correlação de 0,78 (Figura 3B), sendo possível agrupar as amostras em quatro grupos. A variabilidade genética presente em uma espécie de bactéria pode ser demonstrada pelo estudo dos fragmentos de DNA de tamanhos distintos (ERIC-PCR), gerados a partir de uma amplificação de sequências repetitivas existente em seu genoma, por meio da utilização de oligonucleotideos específicos pela PCR. ${ }^{48}$ 


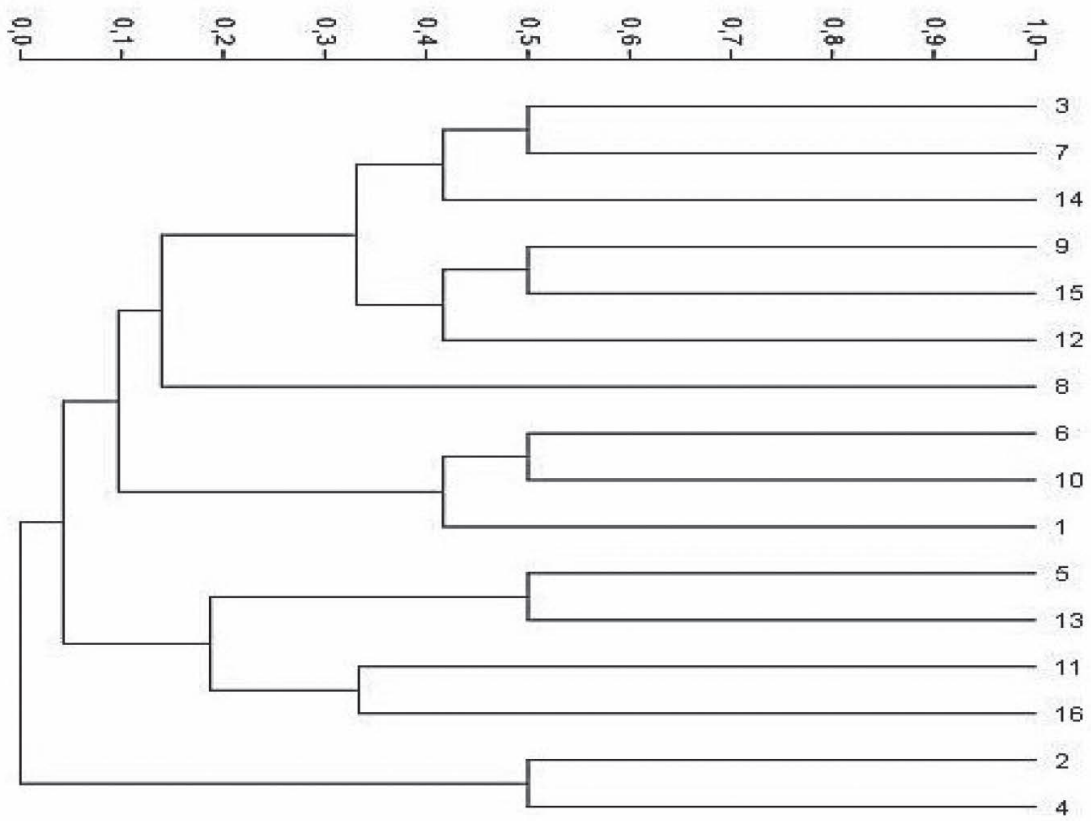

Figura 3B. Teste ERIC-PCR.

O uso da técnica ERIC-PCR também foi eficaz, demonstrando a variabilidade genética e caracterização de amostras de Leishmania chagasi, obtendo resultados confiáveis, sensíveis e específicos, podendo ser utilizada em situações de diagnóstico e diferenciação, além da facilidade na aquisição dos resultados. ${ }^{19}$

Figuras 3 (A e B) representam, respectivamente, dendogramas referentes ao teste de variabilidade genética PCR-RAPD e ERIC-PCR da E. coli isolada de amostras de sorvetes de Araçatuba-SP e região, 2016.

A conservação de bandas, comum em teste PCR-RAPD em espécies próximas, aparece somente em algumas amostras com a mesma procedência (Figura 2), diferenciando apenas as concentrações dos meios em que foram isoladas, porém quando comparadas ao restante das amostras, a persistência era omissa. O perfil gênico encontrado em todas as amostras foi extremamente diversificado.

Ocorrência a ser considerada também é a diferença gênica entre bactérias isoladas de meio de cultivo em concentrações diferenciadas, porém, todas são provenientes de uma mesma amostra, supondo uma contaminação de cepas heterogêneas. 


\section{Conclusão}

As amostras apresentaram alto índice de contaminação por coliformes a $30-35^{\circ} \mathrm{C}$ e coliformes a $45^{\circ} \mathrm{C}$, e positividade para Salmonella spp, tornando o alimento uma ameaça à saúde do consumidor. O teste de suscetibilidade a antimicrobianos da $E$. coli isolada do sorvete expressou resistência e multirresistência, além de decorrência diferenciada para bactérias provenientes de uma mesma amostra. Aspecto discorde numa mesma amostragem também foi encontrado na PCR-RAPD, que detectou índice de polimorfismo, indicando grande variabilidade genética entre as bactérias, considerando fontes distintas de contaminações.

\section{Colaboradores}

Andrade, A. P. e Luche, D. E. D. participaram de todas as etapas do trabalho, desde a concepção do estudo até a versão final. Matos, D. J. participou na orientação deste estudo, visando à parte microbiológica. Cervelatti, E. P. participou na co-orientação, visando à parte de genética molecular do estudo.

Conflito de Interesses: Os autores declaram não haver conflito de interesses.

\section{Referências}

1. Brasil. Agência Nacional de Vigilância Sanitária. Resolução n. 266 de 22 de set. de 2005. Regulamento técnico para fixação de identidade e qualidade de gelados comestíveis e, preparados para gelados comestíveis, pós para o preparo e bases para gelados comestíveis. Diário Oficial da União 23 set. 2005.

2. Brasil. Agência Nacional de Vigilância Sanitária. Portaria n. 379, de 26 de abr. de 1999. Aprova o regulamento técnico referente a gelados comestíveis, preparados, pós para o preparo e bases para gelados comestíveis. Diário Oficial da União 29 abr.1999.

3. Alves ARF. Doenças alimentares de origem bacteriana [dissertação]. [Porto]: Universidade Fernando Pessoa, Faculdade Ciências da Saúde, 2012.

4. São Paulo. Secretaria de Agricultura e Abastecimento. Resolução SAA-03 de 10 de jan. de 2008. Que baixa normas técnicas sobre as condições higiênico-sanitárias mínimas necessárias para aprovação, funcionamento e reaparelhamento dos estabelecimentos destinados a leite e produtos lácteos. Diário Oficial 11 jan. 2008; 118(7):31

5. Baccaro MR, Moreno, AM, Corrêa A, Ferreira AJP, Calderano FF. Resistência antimicrobiana de amostra de Escherichia coli isoladas em fezes de leitões com diarreia. Arq Inst Biol. 2002; 69(2):15-18.

6. Pazianotti L, Bosso AA, Cardoso S, Rezende Costa M, Sivieri K. Características microbiológicas e físico-químicas de sorvetes artesanais e industriais comercializados na região de Arapongas-PR. Rev Inst Latic Cândido Tostes 2010; 65(377):15-20. 
7. Padilha GR. Boas práticas de fabricação em indústria de gelados comestíveis como pré-requisito para implantação do sistema APPCC [Trabalho de Conclusão de Curso]. [Bento Gonçalves]: Instituto Federal do Rio Grande; 2011.

8. Koneman E. As enterobacteriaceae In: Koneman E. Diagnóstico microbiológico. $6^{\mathrm{a}}$ ed. Rio de Janeiro: Guanabara; 2008. p. 208-210.

9. Mikilita IS, Cândido LMB. Fabricação de sorvetes: perigos significativos e pontos críticos de controle. Brasil Alimentos 2004; 26:34-37.

10. Mikilita, IS. Avaliação do estágio de adoção das boas práticas de fabricação pelas indústrias de sorvete da região metropolitana de Curitiba-PR: proposição de um plano de análise de perigos e pontos críticos de controle [dissertação] [Curitiba]: Programa de Pós-Graduação em Tecnologia de Alimentos, Setor de Tecnologia, Universidade Federal do Paraná; 2002.

11. World Health Organization. Food safety and foodborne illness. Reviewed March 2007. Fact sheet no 237 [Internet]. [acesso em: 29 abr. 2017]. Disponível em: https://foodhygiene2010.files.wordpress. com/2010/06/who-food_safety_fact-sheet.pdf

12. Martinez MB, Taddei CR. Enterobacteriaceae. In: Alterthum F. Microbiologia. $9^{a}$ ed. São Paulo: Atheneu; 2015. 293-301

13. Jakabi M, Franco BDGM. Frequência de isolamento de cepas de E. coli patogênica em alimentos de origem animal. Ciênc Tecnol Alim. 1991; 11:170-181.

14. Hobbs BC, Roberts D. Toxinfecções e controle higiênico-sanitário de alimentos. São Paulo: Varela; 1999. $376 \mathrm{p}$.

15. Ribeiro MG, Pinto JPNA, Silva EOTR. Escherichia coli O157:H7 de hambúrguer, leite e outros gêneros alimentícios à colite hemorrágica e síndrome urêmico-hemolítica. Hig Aliment. 1999; 13(66/67):88-99.

16. Mota RA, Silva KPC, Freitas MFL, Porto WJN, Silva LBG. Utilização indiscriminada de antimicrobianos e sua contribuição a multirresistência bacteriana. Braz J Vet Res Anim Sci. 2005; 42(6)465-470.

17. Martho GR, Amabis JM. Biologia das populações. v. 3. Rio de Janeiro: Moderna; 1997.

18. Solé-Cava AM. Biodiversidade molecular e genética da conservação: Biologia Molecular e Evolução. Ribeirão Preto: Holos; 2001.

19. Leal CRB. Uso da ERIC-PCR para caracterização de amostras de Leishmania Chagasi [Tese]. [Campo Grande]: Universidade Federal do Mato Grosso do Sul; 2010.

20. Boreli K, Brito NJN, Santos ECG, Silva GA. Avaliação de coliformes totais e termotolerantes em bebedouros de escolas públicas e ginásios de esportes em um município do Norte de Mato Grosso. REBES Rev. Bras. Educ. e Saúde 2014; 5(1):96-9.

21. Brasil. Agência Nacional de Vigilância Sanitária. Resolução no 12, de 2 de janeiro de 2001. Aprova o regulamento técnico sobre padrões microbiológicos para alimentos. Diário Oficial da União 10 jan. 2001. 
22. Silva N, Junqueira VCA, Silveira NFA. Manual de métodos de análise microbiológica de alimentos. São Paulo: Varela; 2007. 105 p.

23. Bauer AW, Kirby VMM, Sherris JC, Turck M. Antibiotics susceptibility testing by a stantardized single disk method. Am J Clin Pathol. 1965; 45(4):493-496.

24. Clinical and Laboratory Standards Institut. Performace sandards for antimicrobial disk susceptibility tests. $8^{a}$ ed. Pennsylvania: CLSI; 2003.

25. Paradela A, Barroso S. Disseminação de genes de resistência em estirpes clínicas de Escherichia coli [Dissertação]: [Aveiro]: Universidade de Aveiro; 2008.

26. Versalovic J, Koeuth T, Lupski JR. Distribution of repetitive DNA sequences in eubactéria and appplication to fingerprinting of bacterial genomes. Nucleic Acids Res. 1991; 19(24):6823-6831.

27. Trigo VC. Manual prático de higiene e sanidade das unidades de alimentação e nutrição. São Paulo: Varela; 1999.

28. Paiva YF, Silva EV, Araújo AS, Azevedo PTM, Sousa TCA. Condições higiênico-sanitárias de sorvetes do tipo italiano (soft), comercializados em Pombal, Paraíba. Revista Verde de Agroecologia e Desenvolvimento Sustentável 2016; 11(3):75-79.

29. Trabulsi LR, Keller R, Tardelli Gomes TA. Typical and atypical enteropathogenic, Escherichia coli. Emerg Infect Dis. 2002; 8(5):508-513.

30. Whittam TS. Genetic variation and evolutionary processes in natural populations of Escherichia coli. Escherichia coli and Salmonella spp. In: Neidhardt FC, editor. Cellular and molecular biology. Washington (DC): ASM Press; 1996. p. 2708.

31. Falcão DP. Exame microbiológico de sorvetes não pasteurizados. Rev. Saúde pública 1983; 17:2-8.

32. Brasil. Ministério da Agricultura. Decreto no 30691, de 29 março 1952. RIISPOA - Regulamento da Inspeção Industrial e Sanitária de Produtos de Origem Animal. Brasília: Ministério da Agricultura, 1952. Diário Oficial da União 07 jul. 1952.

33. Pupo GM, Karaolis DK, Lan R, Reeves PR. Evolutionary relationships among pathogenic and nonpathogenic Escherichia coli strains inferred from multilocus enzyme electrophoresis and mdh sequence studies. Infect Immun. 1997; 65(7):2685-2692.

34. Queiroz HGS, Sampaio Neta NA, Pinto RS, Rodrigues MCP, Costa JMC. Avaliação da qualidade físico-química e microbiológica de sorvetes do tipo tapioca. Revista Ciência Agronômica 2009; 40(1):60-65.

35. Bryan FL, Teufel P, Riaz S, Roohp S, Qadar F, Malik ZUR. Hazards and critical control points of street-vending operations in a mountain resort town in Pakistan. Journal of Food Protection 1992; 55(9):701-707.

36. Hoffmann FL, Penna ALB, Coelho AR, Mansor AP, Vinturim TM. Qualidade higiênico-sanitária de sorvetes comercializados na cidade de São José do Rio Preto-SP-Brasil. Hig Aliment. 2000; 14(76):62-68.

37. Warke R, Kamat A, Kamat M, Thomas P. Incidence of pathogenic psychotrophs in ice cream sold in some retail outlets in Mumbai, India. Food Control 2000; 11(2):77-83. 
38. Perese JTM, Almeida IAZC, Lima SI, Marques ECA, Rodrigues AS, Fernandes DSG, et al. Surtos de enfermidades transmitidas por alimentos causados por Salmonella enteridis. Rev Saúde Pública1998; 32(5):477-483.

39. Ribeiro Furtini LL, Abreu LR. Utilização de APPCC na indústria de alimentos. Ciênc Agrotec. 2006; 30(2):358-363.

40. Forsythe SJ. Microbiologia da segurança dos alimentos. 2a ed. Porto Alegre: Artmed; 2013.

41. Ribeiro MC, Stelato MM. Microbiologia prática: aplicações de aprendizagem de microbiologia básica. $2^{a}$ ed. São Paulo: Atheneu; 2011.

42. McGeer A. News in antimicrobial resistance: documenting the progress of pathogens. Infect Control Hosp Epidemiol. 2004; 25(2):97-8.

43. Gaite FB, Sáenz AJ, Vidal MV, Castellana Perelló D. Nuevas opciones terapêuticas para el tratamiento de las bactérias multirresistentes en Unidades de Cuidados Intensivos. Rev Esp Quimioter. 2008; 21(1):9-13.

44. Correia CE. Infecções urinárias e susceptibilidade de uropatógenos aos antimicrobianos [Dissertação]. Aveiro: Universidade de Aveiro, Departamento de Biologia; 2009.

45. Tavares JC. Microbiologia e farmacologia simplificada. Rio de Janeiro: Revinter; 2002.

46. Schroeder Carl M, Zhao C, Debroy C, Torcolini J, Zhao S, Branco DG, et al. Antimicrobial resistance of Escherichia coli $\mathrm{O} 157$ isolated from humans, cattle, swine, and food. Appl Environ Microbiol. 2002; 68(2):576-581.

47. Canal N. Caracterização de resistência a antimicrobianos e diversidade genética em Escherichia coli isolada de amostras de água da Lagoa dos Patos, RS [Dissertação]. [Porto Alegre]: Universidade Federal do Rio Grande do Sul, Instituto de Ciências Básicas da Saúde; 2010.

48. Saiki RK, Gelfand DH, Stoffel S. Primer-directed enzymatic amplification of DNA with a thermostable DNA polymerase. Science 1998; 239(4839):487-491.

Recebido: 22/12/2016

Revisado: 20/04/2017

Aceito: 15/05/2017 